\title{
Our Weak Nonlinear Electromagnetic Field (Nemf) that Rules Everything in the Body is Emotionally Sensitive
}

\author{
Maria Kuman* \\ Holistic Research Institute, USA
}

Submission: August 25, 2018; Published: October 09, 2018

*Corresponding author: Maria Kuman, Holistic Research Institute, 1414 Barcelona Dr., Knoxville, TN 37923, USA

Email: holisticare@mariakuman.com

\section{Abstract}

The Russian scientist Shkatov used his patented equipment 'torsemeter' to measure the direction of spinning of our weak NEMF. He found that negative emotions make the torus-shaped NEMF spin faster counterclockwise, while positive emotions make it spin clockwise. In this article, the finding of the Russian scientist Shkatov was compared with measurements with our patented equipment of the energy of the alternating vortices and anti-vortices of our NEMF at positive and negative emotion (or just positive or negative thinking). This comparison (with the help of nonlinear physics) allowed us to see the whole dynamics of our weak NEMF, which rules and regulates everything in the body. This helped us see the role emotions play in our health and in the onset of chronic diseases or cancer.

Keywords: Human nonlinear EMF; EMF spinning at negative emotions; EMF spinning at positive emotions; Our measurements of the nonlinear EMF; Revealing the dynamics of our EMF

\section{Introduction}

Imagine listening to a harmonious classical music. The music is harmonious and pleases your ears because the symphony orchestra has a conductor, who synchronizes the sounds of all musical instruments in his orchestra. This is exactly what the weak nonlinear electromagnetic field does in the body - it synchronizes the work of all cells in the body. When the cells work in perfect harmony, we enjoy perfect health. When one of the organs starts functioning out of synch, we cannot enjoy our health and our life any more. We suffer pain of this organ, and pain is the cry of the body for help.

What did cause the 'false sounding' of the organ that became sick? The answer is - stress. How stress does this? The stress causes delay because the body needs to stop what it was doing at the moment and mobilize for response to the stressor - to fight or flight, adapt or resist. Especially damaging is strong or prolonged stress, which is a chain of stressors acting through small intervals of time. The delays they create accumulate and the body cannot compensate for the large delays they create [1].

For periodic reactions, the delays are called phase shifts. The phase shifts, caused by the stress-induced delays, are the ones that desynchronize the harmonic work of the cells. They move along the chain of organs following the energy cycle of organs' activity [2] until the genetically weak organ, which does not have enough energy to propel them, absorbs them. This makes the functioning of the genetically weak organ even more sluggish, which manifests in pain of this organ. We call it chronic disease [1].

This simple explanation is in full agreement with the findings of Selye $[3,4]$ who spent 40 years of his life studding stress and who was the first to use the name psychological stress. He borrowed the word stress from engineering and he explained that just as stress applied to a material cracks it at the weakest place, strong or prolonged psychological stress "cracks" the body at the weakest place - the genetically inherited weak organ of the body. In this way, he explained his finding that the same stress causes different chronic diseases (or cancer) in different individuals.

Now, let's go back to where we started. Since our weak NEMF synchronizes the work of all cells in the body and stress is the one that desynchronizes them through the phase shifts it causes, we should be able to cure the induced-by-stress diseases (chronic diseases or cancer - it depends on genetic predisposition) with restoring the normal NEMF, which has been distorted by the stress. This is in full agreement with what we said in our previous article: Physics not Chemistry Is Going to Solve the Cancer Problem [5].

The Direction of Spinning of our NEMF is Ruled by Emotions. When Combined with our Measurements it Gives the Whole Dynamics of our NEMF

When we say stress, we mean negative stress, which is also called distress. What happens to our torus-shaped NEMF (Figure 
1) when we experience distress? The Russian scientist Shkatov developed and patented equipment, called 'torsemeter', which allows him to measure the spinning of our NEMF. He found that at negative emotions (distress) the torus-shaped NEMF spins counterclockwise [6].

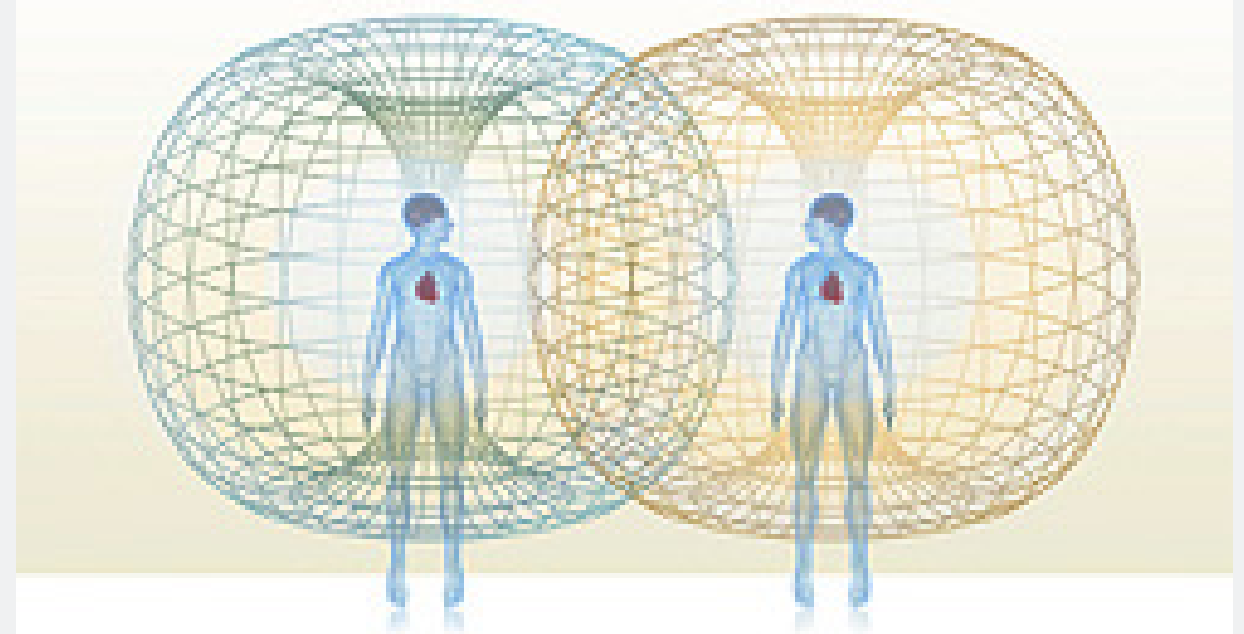

Figure 1: The human torus-shaped NEMF.
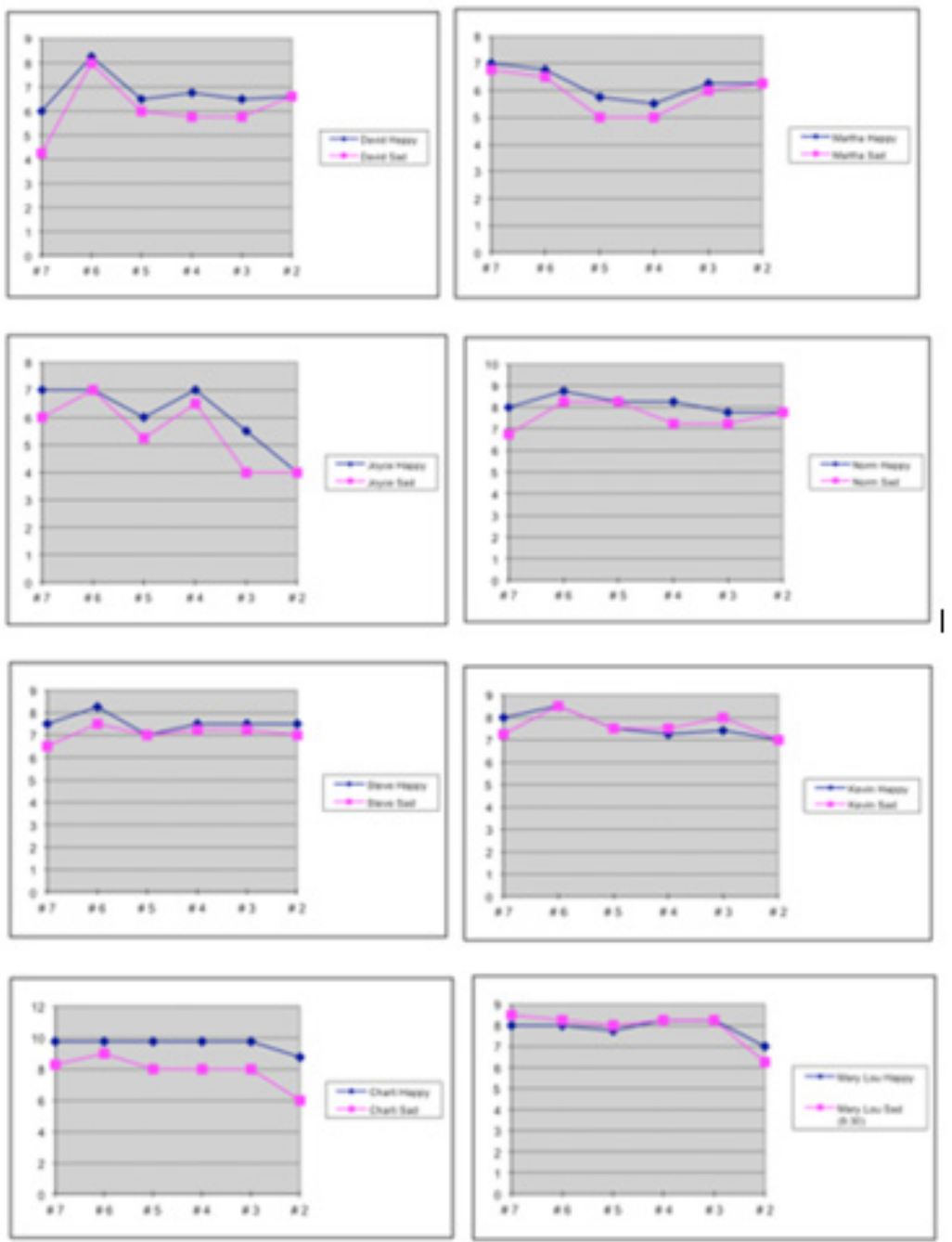

Figure 2: The energy of our NEMF measured at its alternating vortices and anti-vortices pictured on Figure 3. 
We measured the weak NEMF with our patented supersensitive energy meter and we found that at negative emotions (or just negative thinking) the NEMF looses energy (Figure 2). Not only is the total energy of the NEMF lower, it is more imbalanced because the genetically weak organ drops in energy maximum. This means that each distress takes us a step farther to a chronic disease or cancer of the genetically inherited weak organ [7].

But is there something that we can do to prevent the chronic disease or cancer? Measurements of Shkatov revealed that at positive emotions the torus-shaped NEMF spins clockwise [6]. Our measurements of NEMF revealed that at positive emotions (or just positive thinking) the energy of the NEMF increases and becomes more balanced (Figure 2). This means that each positive emotion (or just positive thought) is making you healthier [7]. Perfectly balanced NEMF is the healthiest.

Nonlinear Physics needs to step in to explain why the things are the way we found them. There is a rule of the folded fingers of the right hand, which states that if the folded fingers are curved in direction of the electric currents, the thumb would show the direction of the magnetic field induced by the currents. Let us apply this to our spinning NEMF.

At negative emotions (or just negative thinking), the counterclockwise spinning of our NEMF will induce counterclockwise currents. Let's orient the fingers of our right hand counterclockwise, then the thumb would show direction outward for the magnetic field, which means our NEMF will be loosing magnetic energy at negative emotions (or just negative thinking) [6].

At positive emotions (or just positive thinking), the clockwise spinning of our NEMF will induce clockwise currents. Let's orient the fingers of our right hand clockwise, and then the thumb would show direction inward for the magnetic field, which means our NEMF will be gaining magnetic energy at positive emotions (or just positive thinking) [7] (Figure 3).

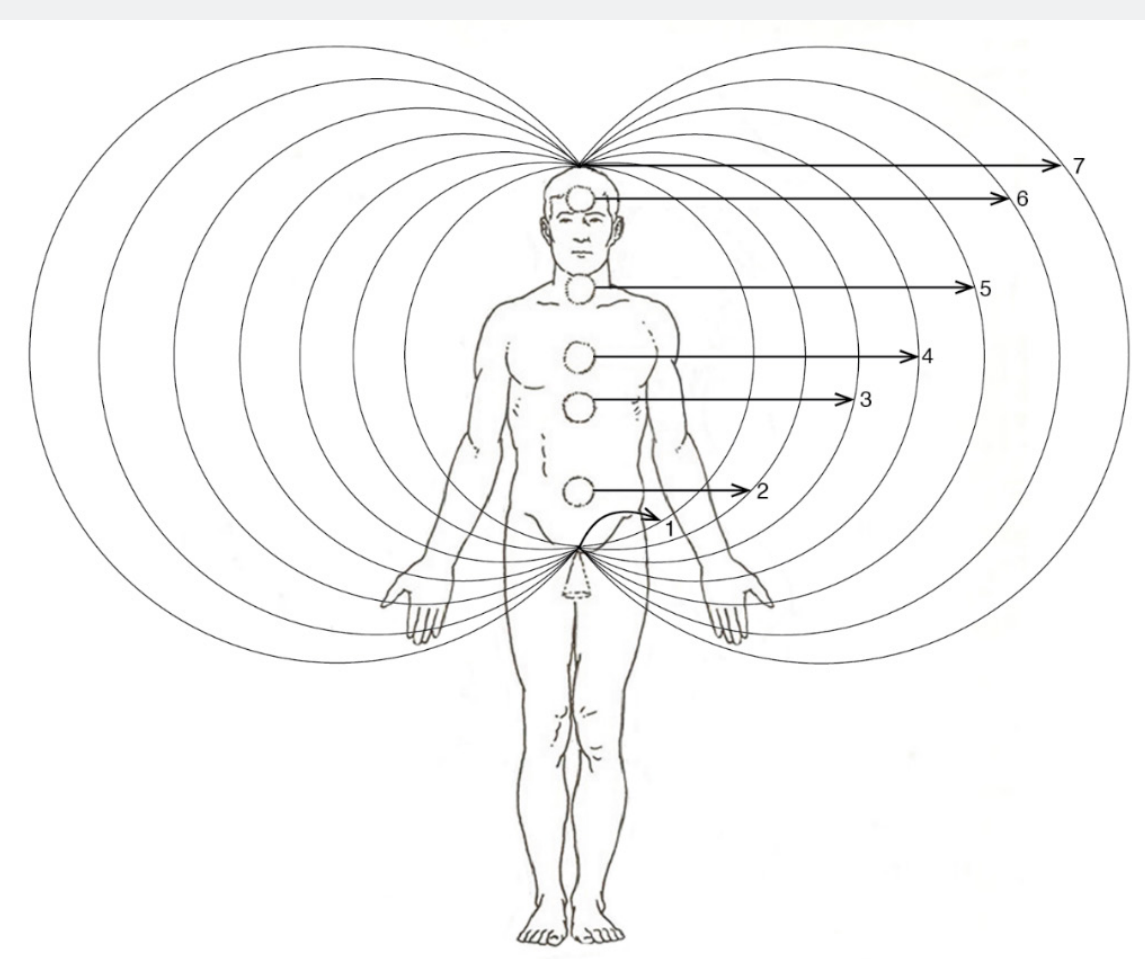

Figure 3: The alternating vortices and anti-vortices of our torus-shaped NEMF.

However, the wise ancient Chinese men used to say [8]: avoid pursuing big goals in life, but if you fail in pursuing your goal, you need to have 3 to 4 smaller goals the successful achievement of which will compensate for your failure in pursuing the first goal. This means that if we have problem balancing our emotions, it is because we need three to four positive emotions to compensate for one negative emotion.

Interestingly, contemporary studies of stress found the same ratio. When comparing the biochemical substances released at negative emotion (distress) with the amount of biochemical substances released at positive emotions, the scientist found the same ratio 1: 3-4 [9].

\section{Conclusion}

Now, let's go back to the spinning of our NEMF. If 3 to 4 positive emotions are necessary to compensate for one negative emotion, this means that at negative emotions (when the torus-shaped NEMF spins counterclockwise), it must spin 3 to 4 time faster. Only then would the lost energy at negative emotions be compensated by 3 to 4 positive emotions.

The large amount of energy lost at negative emotions explains the ancient wisdom of the Hindus "do everything to avoid anger because anger is a very destructive emotion. Always remember that 'Anger' is only one letter away from 'Danger"' [6]. The advice 
of the ancient Hindus was: Only the dumb people become angry. The smart people know that they need to stop the oncoming anger as soon as they notice that they are getting irritated.

\section{References}

1. Kuman M (1993) What Everybody Needs to Know about Chronic Pain Chronic Diseases, and Cancer, Health and Happiness Books.

2. Kuman M (1997) Modern Aspects of Ancient Acupuncture, Health and Happiness Books.

3. Selye H (1976) Stress in Health and Disease. Butterworth, Boston London.
4. Selye H (1956) The Stress of Life, New York, USA.

5. Kuman M (2018) Research in Medicine and Engineering Sciences 5(4)

6. Kuman M (2017) Same Fields and Dynamics in Stars and Man, Health and Heppiness Books.

7. Kuman M (2015) Quantum Mind and Quantum Growth, Health and Heppiness Books.

8. Veith I, Hang Ti Nei Ching Sue Wen, London (1971).

9. Actualnie Problemi Stressa, Kishinev (1976).

\section{Your next submission with Juniper Publishers} will reach you the below assets

- Quality Editorial service

- Swift Peer Review

- Reprints availability

- E-prints Service

- Manuscript Podcast for convenient understanding

- Global attainment for your research

- Manuscript accessibility in different formats

( Pdf, E-pub, Full Text, Audio)

- Unceasing customer service

Track the below URL for one-step submission https://juniperpublishers.com/online-submission.php 